\title{
HUBUNGAN ANTARA INISIASI MENYUSUI DINI DENGAN INVOLUSI UTERUS PADA IBU POST PARTUM NORMAL DI POSKESDES MELATI DESA GARON KAB. MADIUN
}

\author{
Wida Rahma Arwiyantasari' ${ }^{1}$, Edy Bachrun²), Riska Ratnawati3) \\ ${ }^{1}$ widarahmaarwiyantasari@ymail.com \\ 1) Akademi Kebidanan Muhammadiyah Madiun \\ J1. Lumbung Hidup No. 2A Kel. Ngegong Kec. Manguharjo Kota Madiun \\ ${ }^{2,3}$ Prodi Kesehatan Masyarakat STIKES Bhakti Husada Mulia Madiun \\ J1. Taman Praja No. 25 Kel. Mojorejo, Kec. Taman Kota Madiun
}

\begin{abstract}
Abstrak
Angka kematian ibu di Indonesia karena perdarahan post partum mempunyai peringkat yang tinggi salah satu penyebab perdarahannya adalah atonia uteri. Involusi dapat dipercepat prosesnya bila ibu menyusui bayinya. Tujuan penelitian ini adalah untuk mengetahui hubungan inisiasi menyusui dini dengan involusi uterus. Penelitian ini menggunakan metode analitik dengan pendekatan cross sectional. Populasi dan sampel yang digunakan adalah ibu bersalin spontan di Poskesdes Melati sebanyak 30 pasien dan tehnik sampling menggunakan Aksidental sampling. Dari hasil penelitian didapatkan setelah dilakukan inisiasi menyusui dini ada 17 pasien yang mengalami kondisi involusi uterus keras, kontraksi kuat dan ada 2 pasien yang mengalami kondisi involusi uterus lunak, kontraksi lemah. Sedangkan yang tidak dilakukan inisiasi menyusui dini ada 9 pasien yang mengalami kondisi involusi uterus keras, kontraksi kuat dan 2 pasien mengalami kondisi involusi lunak, kontraksi lemah. Dari hasil uji statistik fisher exact, maka ternyata p hitung lebih besar dari 0,05. Karena p hitung lebih besar dari $\alpha(0,06>0,05)$, maka dapat dinyatakan bahwa terdapat hubungan antara inisiasi menyusui dini dengan involusi uterus. Diharapkan ibu selalu memberikan ASI pada bayinya agar proses involusi uterus berjalan dengan baik dan kebutuhan gizi bayi bisa terpenuhi.
\end{abstract}

Kata kunci : Inisiasi Menyusui Dini, Involusi Uterus, Post Partum

\begin{abstract}
The maternal mortality rate in Indonesia due to post partum hemorrhage has a high ranking. One of the causes of bleeding is uterine atony. The process can be accelerated if the mother feeds her baby. The purpose of this study was to determine the relationship of initiation of early breastfeeding with uterine involution. This study uses an analytical method with a cross sectional approach. The population and sample used were spontaneous maternity at 30 Melati Poskesdes and the sampling technique used accidental sampling. From the results of the study, it was found that after initiation of early breastfeeding there were 17 patients who experienced conditions of hard uterine involution, strong contractions and 2 patients who experienced soft uterine involution, weak contractions. Whereas those who did not initiate early breastfeeding had 9 patients who experienced conditions of hard uterine involution, strong contractions and 2 patients experiencing conditions of soft involution, weak contractions. From the results of the fisher exact statistics, it turns out that the $p$ count is greater than 0.05. Because $p$ count is greater than $\alpha$ (0.06> 0.05), it can be stated that there is a relationship between the initiation of early breastfeeding and uterine involution. It is hoped that the mother always gives breast milk to her baby so that the uterine involution process runs well and the nutritional needs of the baby can be fulfilled.
\end{abstract}

Keywords: Early Breastfeeding Initiation, Uterine Involution, Post Partum

\section{Pendahuluan}

Periode post partum merupakan masa lahirnya plasenta, selaput janin, dan kembalinya organ reproduksi wanita pada kondisi tidak hamil. Wanita yang hamil akan mengalami perubahan dalam tubuhnya yaitu otot uterus yang disebut hipertropi dan hyperplasia. 
Ketika hamil, uterus seorang perempuan menjadi berkembang atau membesar sehingga mampu menampung pertumbuhan dan perkembangan janin sampai cukup bulan dengan berat lebih dari 2500 gram. Adapun berat rahim yang semula hanya 30-50 gram menjadi satu kilogram ${ }^{[1]}$. Proses kembalinya uterus pada keadaan semula atau keadaan sebelum hamil disebut dengan involusi uteri ${ }^{[2]}$. Faktor yang mempengaruhi involusi uterus antara lain senam nifas, mobilisasi dini, inisiasi menyusui dini, gizi, psikologis dan faktor usia dan paritas ibu ${ }^{[3]}$.

Angka Kematian Ibu yang disebabkan oleh perdarahan proposinya berkisar antara kurang dari 10 persen sampai hampir 60 persen. Walaupun seorang perempuan bertahan hidup setelah mengalami pendarahan pasca persalinan, namun ia akan menderita akibat kekurangan darah yang berat (anemia berat) dan akan mengalami masalah kesehatan yang berkepanjangan $^{[4]}$.

Berdasarkan penelitian, diperoleh informasi bahwa angka kematian ibu di Indonesia karena perdarahan post partum mempunyai peringkat yang tinggi salah satu penyebab perdarahannya adalah Atonia Uteri atau tidak adanya kontraksi pada uterus. Hasil penelitian menunjukkan bahwa 10 $\%$ kematian maternal nonaborsi dan sekitar $8 \%$ seluruh kehamilan mengalami komplikasi perdarahan pasca partum $^{[5]}$. Inisiasi Menyusui Dini merupakan faktor yang dapat mempercepat proses involusi uterus. Hal ini disebabkan karena isapan bayi pada payudara dilanjutkan melalui saraf ke kelenjar hipofise di otak yang mengeluarkan hormon oksitosin ${ }^{[6]}$.

Penyebab dari perdarahan pasca persalinan antara lain atonia uteri (50$60 \%$ ) yang disebabkan proses persalinan yang lama, retensio plasenta (16-17\%) yang disebabkan karena implantasi plasenta, retensio plasenta (23-24\%), laserasi jalan lahir (4-5\%) karena robekan jalan lahir yang lebar serta karena kelainan pembekuan darah ${ }^{[7]}$.
Adanya isapan bayi pada puting susu ibu menyebabkanoksitosin akan keluarlebih banyak. Hal ini menguntungkan karena otot-otot polos rahim akan terus berkontraksi. Artinya rahim akan berkontraksi lebih kuat sehingga perdarahan pascasalin dapat dicegah ${ }^{[8]}$.

Berdasarkan informasi yang di dapat peneliti di Poskesdes Melati diperoleh rata - rata pasien selama 3 bulan sekitar $11 \mathrm{ibu}$ post partum normal didukung dengan lingkungan rooming in/rawat gabung sehingga ibu dapat menyusui bayinya. Bukti lain menunjukkan, pada 2 ibu post partum mengalami perdarahan kurang lebih 500 cc dikarenakan ibu belum menyusui dini. Kemungkinan pada pasien tersebut ditemukan kontraksi uterus yang lembek. Oleh karena itu ibu dianjurkan untuk segera menyusui bayinya diharapkan efek bayi mengisap puting susu akan merangsang hormon oksitosin keluar sehingga merangsang otot uterus untuk berkontraksi dengan baik dan didapatkan secara palpasi uterus ibu menjadi keras serta jumlah lochea rubra tidak berlebihan. Tujuan penelitian ini adalah untuk mengetahui hubungan antara inisiasi menyusui dini dengan involusi uteri di Poskesdes Melati Desa Garon Kab. Madiun.

\section{Metode Penelitian}

Jenis penelitian dalam penelitian ini adalah analitik. Desain penelitian yang digunakan dalam penelitian ini adalah survey cross sectional. Menggunakan Aksidental Sampling berjumlah $30 \mathrm{ibu}$ post partum normal di Poskesdes Melati Desa Garon Kab. Madiun pada bulan Mei - Juli Tehnik pengambilan sampel di dasarkan pada pertimbangan yang dibuat oleh peneliti berdasarkan kriteria inklusi dan eksklusi yang telah ditentukan oleh peneliti.

Kriteria Inklusi dalam penelitian ini adalah :

1) Ibu post partum normal di Poskesdes Melati Desa Garon Kab. Madiun.

2) Ibu yang menyusukan ASI.

3) Tidak ada penyulit dalam persalinan. 
4) Kondisi fisik dan psikologis ibu post partum sehat.

5) Persalinan maksimal tiga kali.

Kriteria eksklusi dalam penelitian ini adalah :

1) Ibu post partum normal di Poskesdes Melati Desa Garon Kab. Madiun yang memenuhi kriteria inklusi tetapi menolak menjadi responden.

2) Ibu post partum normal di Poskesdes Melati Desa Garon Kab. Madiun dengan indikasi kanker payudara.

3) Ibu post partum normal di Poskesdes Melati Desa Garon Kab. Madiun dengan indikasi abses payudara.

4) Usia lebih dari 35 tahun.

5) Persalinan lebih dari empat kali ( Grandemultipara )

Alat pengumpulan data dalam penelitian ini adalah observasi dengan lembar ceklis yang digunakan untuk mengetahui menyusui dini dan involusi uterus. Dalam melakukan observasi secara langsung peneliti memberi tanda ceklis pada lembar observasi kondisi ibu post partum yang menyusui dini dan kondisi ibu yang mengalami involusi uteri setelah persalinan. Bentuk atau jenis pertanyaan yang akan dilakukan yaitu peneliti menggunakan kriteria sebagai berikut : dikatakan Ya apabila ibu melakukan aktifitas menyusui dini 0 $-\leq 1$ jam, Tidak apabila $>1$ jam. Untuk mengukur involusi uteri, kriteria Normal apabila uterus teraba keras, kontraksi uterus kuat, TFU. Kriteria Abnormal apabila uterus teraba lunak, kontraksi uterus lunak, TFU. Jumlah pertanyaan dalam penelitian ini sebanyak 2 butir pertanyaan. Langkah langkah analisa data yang dilakukan antara lain Editing, Coding, Tabulating.

\section{Hasil dan Pembahasan}

Penelitian ini dilakukan pada ibu bersalin spontan dan memperoleh responden sebanyak 30 orang dengan penyajian dibagi dua yaitu data umum dan data khusus. Data umum menyajikan tentang demografi responden yang terdiri dari umur, pekerjaan, dan pendidikan. Data khusus menyajikan tentang hubungan inisiasi menyusui dini dengan involusi uterus.

Tabel 1. Distribusi Frekuensi Karakteristik

\begin{tabular}{|c|c|c|c|}
\hline No. & Data Umum & $\mathrm{F}$ & $\%$ \\
\hline \multirow[t]{4}{*}{1 . } & Usia & & \\
\hline & - $19-28$ & 18 & 60 \\
\hline & - $29-38$ & 8 & 27 \\
\hline & - $39-48$ & 4 & 13 \\
\hline \multirow[t]{4}{*}{2.} & Pendidikan & & \\
\hline & - SD & 1 & 3 \\
\hline & - SMP & 10 & 33 \\
\hline & - SMU & 19 & 64 \\
\hline \multirow[t]{13}{*}{3.} & Pekerjaan & & \\
\hline & - Tidak bekerja & 0 & 0 \\
\hline & - Ibu rumah tangga & 24 & 80 \\
\hline & - Swasta & 6 & 20 \\
\hline & Data Khusus & & \\
\hline & Inisiasi Menyusui Dini & & \\
\hline & - Ya & 19 & 63 \\
\hline & - Tidak & 11 & 37 \\
\hline & Kondisi & & \\
\hline & Uterus & 26 & 7 \\
\hline & - Keras, kontraksi & 4 & 14 \\
\hline & kuat & & \\
\hline & - Lunak, kontraksi & & \\
\hline
\end{tabular}

Dapat diketahui dari 30 responden didapatkan sebagian besar responden berusia $19-28$ tahun sebanyak 18 orang (60\%) dan sebagian kecil berusia 39 48 tahun sebanyak 4 orang (13\%). Penelitian menyatakan bahwa $81,2 \%$ responden yang mempunyai umur resiko ( > 35 tahun) mengalami involusi uterus yang tidak normal dibandingkan kelompok umur yang tidak berisiko 20 35 tahun). ${ }^{[9]}$ Hasil temuan tahun 2004 yang menemukan bahwa perdarahan pascasalin cenderung meningkat yang disebabkan salah satu faktor usia ibu yaitu $39-48$ tahun $^{[10]}$.

Sebagian besar responden berpendidikan SMU (64\%) sebanyak 19 orang dan sebagian kecil berpendidikan SD hanya 1 orang (3\%). Semakin tinggi pendidikan semakin mudah menerima informasi, sehingga semakin banyak pula pengetahuan yang dimiliki begitu pula sebaliknya. Semakin rendah tingkat pendidikan maka akan sulit mencerna pesan yang disampaikan ${ }^{[11]}$. Faktor pendidikan ikut mempengaruhi tingkat pengetahuan ibu tentang pentingnya 
menyusui dini.

Sebagian besar responden bekerja sebagai ibu rumah tangga sebanyak 24 orang $(80 \%)$ dan sebagian kecil bekerja dalam bidang swasta sebanyak 6 orang (20\%). Wanita di kelas sosio ekonomi yang paling rendah memiliki faktor risiko lebih besar daripada faktor risiko pada wanita di kelas yang paling tinggi: ${ }^{[12]}$ Faktor resiko yg di maksud adalah faktor - faktor yang mempengaruhi ibu menyusui, mungkin ibu tidak terlalu percaya diri sehingga ia enggan untuk menyusui bayinya.

Distribusi frekuensi berdasarkan jumlah responden yang melakukan inisiasi menyusui dini menunjukkan bahwa sebagian besar responden yang melakukan inisiasi menyusui dini sebanyak 19 orang (63\%) dan sebagian kecil yang tidak melakukan insiasi menyusui dini sebanyak 11 orang $(37 \%)$.

Distribusi frekuensi berdasarkan kondisi involusi uterus menunjukkan bahwa sebagian besar responden mengalami kondisi involusi keras dan kontraksi kuat sebanyak 26 orang (87\%) dan sebagian kecil mengalami kondisi involusi lunak dan kontraksi lemah sebanyak 4 orang (14\%).

\section{Hubungan Inisiasi Menyusui Dini dengan Involusi Uterus}

Tabel 2. Hubungan Insiasi Menyusui Dini dengan Involusi Uterus

\begin{tabular}{lccc}
\hline \multirow{2}{*}{$\begin{array}{c}\text { Kondisi } \\
\text { Involusi }\end{array}$} & \multicolumn{2}{c}{$\begin{array}{c}\text { Inisiasi Menyusui } \\
\text { Dini }\end{array}$} & $\mathrm{F}(\%)$ \\
\cline { 2 - 3 } Uterus & Ya & Tidak & \\
\hline Keras, & 17 & 9 & 26 \\
kontraksi & $(65,3 \%)$ & $(34,6 \%)$ & $(100 \%)$ \\
kuat & & & \\
Lunak, & 2 & 2 & 4 \\
kontraksi & $(50 \%)$ & $(50 \%)$ & $(100 \%)$ \\
lemah. & & & \\
Jumlah & 19 & 11 & 30 \\
& $(63,3 \%)$ & $(36,6 \%)$ & $(100 \%)$ \\
\hline
\end{tabular}

Dapat diketahui bahwa pasien yang mengalami kondisi involusi uterus keras, kontraksi kuat ada 17 pasien $(65,3 \%)$ setelah dilakukan inisiasi menyusui dini dan ada 9 pasien $(34,6 \%)$ yang mengalami kondisi involusi yang sama namun tidak dilakukan inisiasi menyusui dini. Sedangkan terdapat 2 pasien yang mengalami kondisi involusi uterus lunak, kontraksi lemah setelah di lakukan inisiasi menyusui dini dan 2 pasien mengalami kondisi involusi yang sama namun tidak dilakukan inisiasi menyusui dini. Berdasarkan tabel 1.9. diketahui bahwa hasil uji fisher exact, maka ternyata $\mathrm{p}$ hitung sebesar 0,06 , bila taraf kesalahan $\alpha$ ditetapkan 5\% $(0,05)$ maka ternyata $p$ hitung lebih besar dari 0,05 . Karena $\mathrm{p}$ hitung lebih besar dari $\alpha$ $(0,06>0,05)$, maka dapat dinyatakan bahwa terdapat hubungan antara inisiasi menyusui dini dengan involusi uterus.

Hasil penelitian tersebut sesuai dengan penelitian sebelumnya bahwa sewaktu bayi menyusu, ujung saraf peraba yang terdapat pada puting susu terangsang. Rangsangan tersebut oleh serabut afferent dibawa ke hipotalamus di dasar otak, lalu memacu hipofise anterior untuk mengeluarkan hormon prolaktin dalam darah ${ }^{[9]}$. Melalui sirkulasi prolaktin memacu kelenjar (alveoli) untuk memproduksi air susu. Jumlah prolaktin yang disekresi dan jumlah susu yang diproduksi berkaitan dengan stimulus isapan, yaitu frekuensi, intensitas, dan lamanya bayi menghisap. Sehingga semakin ibu lebih aktif menyusui bayinya maka jumlah produksi susu akan meningkat. Ibu yang melakukan IMD akan akan berhasil memberikan ASI eksklusif kepada bayi mereka. Namun, pada kenyataannya masih ada ibu yang gagal memberikan ASI eksklusif walaupun telah melakukan IMD ${ }^{[13]}$. Adanya isapan bayi pada puting susu ibu menyebabkan oksitosin akan keluar lebih banyak. Hal ini menguntungkan karena otot-otot polos rahim akan terus berkontraksi ${ }^{[14]}$. Semakin banyak dilakukan IMD setelah lahir maka akan sangat menguntungkan bagi ibu terutama dalam proses involusi uterus. Pemberian ASI dalam jangka satu jam setelah melahirkan akan meningkatkan ikatan antara ibu dan anak ${ }^{[15]}$. Perhatian yang diberikan oleh petugas kesehatan yang membatu persalinan sangat menentukan 
pelaksanaan IMD dan kebutuhan dibuat kebijakan meningkatkan perhatian masyarakat untuk melaksanakan $\mathrm{IMD}^{[16]}$.

Ada beberapa faktor yang mempengaruhi involusi uterus, diantaranya mobilisasi dini, usia, paritas, dan menyusui dini. IMD dapat mengurangi terjadinya perdarahan pasca salin sebesar 25\% ${ }^{[17]}$. Hasil Fisher Exact Test juga menunjukkan adanya hubungan antara waktu pemberian ASI pertama dengan involusi uterus ibu post partum normal hari ke- $7^{[18]}$.

Menurut asumsi peneliti ada hubungan inisiasi menyusui dini dengan involusi uterus dimana bayi mulai menghisap puting ibu yang akan merangsang pengeluaran hormon oksitosin yang mengakibatkan kontraksi uterus ibu sehingga proses involusi uterus ibu dapat berjalan normal.

\section{Kesimpulan}

Setelah dilakukan perhitungan dengan tabel silang menggunakan uji fisher exact diperoleh kesimpulan bahwa ada hubungan antara inisiasi menyusui dini dengan involusi uterus pada ibu post partum. Diharapkan ibu selalu memberikan ASI pada bayinya agar proses involusi uterus berjalan dengan baik dan kebutuhan gizi bayi bisa terpenuhi.

\section{Daftar Pustaka}

[1] Verralls, Sylvia. Anatomi dan Fisiologi Terapan dalam Kebidanan. Jakarta: EGC. 2003.

[2] Varney, Helen. Buku Ajar Asuhan Kebidanan. Edisi 4. Jakarta: EGC. 2010.

[3] Prawiroharjo, Sarwono. Ilmu Kebidanan. Jakarta: YBS. 2009.

[4] Riskesdas. Riset Kesehatan Dasar. Jakarta: Departemen Kesehatan, Republik Indonesia. 2007.

[5] Bobak, dkk. Buku Ajar Keperawatan Maternitas. Jakarta : EGC. 2004.
[6] Ambarwati, Eny Ratna. Asuhan

Kebidanan Masa Nifas.

Yogyakarta: Nuha Medika. 2010.

[7] Moedjiarto, Sarmini. Karakteristik Ibu yang Berhubungan dengan Perdarahan Post Partum di Rumah Bersalin Medika Utama Wonokupang Balongbendo Sidoarjo Tahun 2009. Jurnal Poltekkes Majapahit. 2011. 3 (1).

[8] Jolly, A., Sebire, N., Harris, J., Robinson, S., \& Regan,L. The risk associated with pregnancy in women age 35 year or older. Hum Reprod. 2000. 15 (11): 2433-7.

[9] Mayasari, Ferdina Fitriana; Meikawati, Wulandari; Astuti, Rahayu. Faktor-Faktor Yang Mempengaruhi Involusi Uterus (Studi Kasus di BPM Idariyani dan BPM Sri Pilih Retno Tahun 2014). Jurnal Kesehatan Masyarakat Indonesia. 2015.10(1).

[10] Joke, M.J., Bais, Eskes, M., Pel, M., Gouke, J., Bonsel \& Bleker O.P. Pasca salin haemorrhage in nulliparous women: incidence and risk factors in low and high risk women a Dutch populationbased cohort study on standard (e"500 $\mathrm{ml})$ and severe $(\mathrm{e} " 1000 \mathrm{ml})$ pasca salin haemorrhage. Obstet Gynecol Reprod Biol. 2004.115:166-72.

[11] Nursalam; Siti Pariani. Pendekatan Praktis Metodologi Riset Keperawatan. Jakarta: CV. Sagung Setyo. 2001.

[12] Rasjidi, I. Epidemiologi Kanker Pada Wanita. Jakarta: Sagung Setyo. 2015.

[13] Rahayu RD, Kuswati, Kurniawati A. Keberhasilan Inisiasi Menyusu Dini (IMD) dan Lama Pemberian ASI. Jurnal Terpadu Ilmu Kesehatan Jilid 1. 2012.

[14] Sumarah et al. Pengaruh Inisiasi Menyusu Dini Terhadap Jumlah Perdarahan Pasca Persalinan. Jurnal Kesehatan Reproduksi, 2014. 1(1). 
[15] Himani, Kaur B, Kumar P. Effect of initiation of breastfeeding within one hour of delivery on maternal infant bonding. Nursing and Midwifery Research Journal. 2011.7(3).

[16] Tawiah AC, Kirkwood BR, Edmond K, Bazzano A, Hill Z. Early initiation of beastfeeding in Ghana: barriers and facilitators. Journal of Perinatology. 2008. 28, S46-S52.
[17] Tsu, V.D., Mai, T.T.P., Nguyen, Y.H. \& Luu, H.T.T. Reducing pasca salin hemorrhage in Vietnam: assessing the effectiveness of active Management of third stage labor. J Obstet Gynaecol Res. 2006. 32(10): 489-96.

[18] Syelvi; Sami, Siti Fadma. Hubungan Inisiasi Menyusui dengan Involusi Uterus Ibu Post Partum Normal Hari Ke-7. Jurnal Stikes YARSI. 2013. 